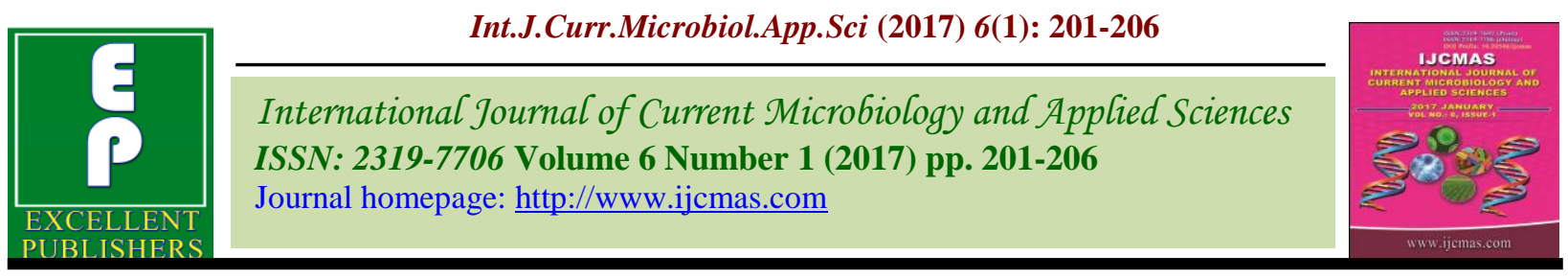

Original Research Article

http://dx.doi.org/10.20546/ijcmas.2017.601.025

\title{
An Audit of Sharp Injuries at a Tertiary Care Hospital in Mumbai, India
}

\author{
Mrudul Randive*, Anita Ramchandran, Dilip Turbadkar and Sujata Baveja \\ Department of Microbiology, Lokmanya Tilak Municipal Medical College and \\ General Hospital, Mumbai - 400 022, India \\ *Corresponding author
}

\begin{tabular}{|c|c|}
\hline & A B S T R A C T \\
\hline & \multirow{6}{*}{$\begin{array}{l}\text { Sharp injuries previously known as Needle stick injuries (NSIs) are an occupational hazard } \\
\text { for Health care workers (HCWs) contributed by factors like work stress, inadequate } \\
\text { experience and training. The aim of the study was to analyse the risk factors for } \\
\text { developing sharp injuries and the subsequent measures taken. A retrospective analysis of } \\
\text { all the Sharp injuries reported in a tertiary care centre from January } 2014 \text { to June } 2015 \text { was } \\
\text { carried out. A total of } 105 \text { Sharp injuries were reported over } 1 \frac{1}{1} 2 \text { years out of which } \\
\text { maximum were students ( } 70.4 \% \text { ) and in the age group of } 17-24 \text { years }(55.43 \%) \text {. Most of } \\
\text { the injuries ( } 28.6 \% \text { ) occurred in the medicine department. } 61 \% \text { injuries occurred after the } \\
\text { use of sharps on patients. Almost all ( } 96 \% \text { ) were self-inflicted. 93\% injuries were } \\
\text { superficial cuts and 5\% were splash. Hollow bore needles caused } 82.85 \% \text { sharp injuries } \\
\text { and recapping was reported in } 17 \% \text { instances. Serostatus of the source was not known in } \\
81 \% \text { cases. 53\% injuries were reported by HCWs with work experience of less than a } \\
\text { year.18.1\% cases had overworked on the previous day (>8hours) or in the previous week } \\
(>48 \text { hours). } 16.2 \% \text { of the HCWs were not vaccinated against Hepatitis B virus. } 61 \% \\
\text { HCWs started the PEP within } 2 \text { hours. All the HCWs were tested for baseline status of } \\
\text { HBsAg, HCV and HIV antibodies. Appropriate training and precautions regarding the } \\
\text { common risk factors is essential for reducing Sharp injuries. }\end{array}$} \\
\hline Keywords & \\
\hline $\begin{array}{l}\text { Sharp injuries, } \\
\text { Healthcare } \\
\text { workers, } \\
\text { Recapping. }\end{array}$ & \\
\hline Article Info & \\
\hline $\begin{array}{l}\text { Accepted: } \\
\text { 12 December } 2016 \\
\text { Available Online: } \\
\text { 10 January } 2017\end{array}$ & \\
\hline & \\
\hline
\end{tabular}

\section{Introduction}

Percutaneous injuries, caused by needle sticks and other sharps, are a serious concern for all healthcare workers (HCWs) and pose a significant risk of occupational transmission of blood borne pathogens. Sharp injury or Needle stick injury (NSI) is any cut or prick to the respondents by a needle or sharp object previously used on a patient; it is work related and sustained within the hospital premises. Various factors like type and design of needle, recapping activity, collision between HCWs or sharps, manipulating needles in patient line related work, passing/ handling devices or failure to dispose of the needle in puncture proof containers are the various risk factors. The level of risk is directly proportional to the risk factors and the precautions observed. All categories of HCWs are at an increased risk of accidental sharps injuries (Sumathi et al., 2010). The level of risk depends on the number of patients with that infection in the health care facility and the precautions the health care workers observe while dealing these patients. There are more than 20 blood-borne diseases, but those of primary significance to health care workers are hepatitis due to either the hepatitis $\mathrm{B}$ virus (HBV) or hepatitis $\mathrm{C}$ virus 
(HCV) and acquired immunodeficiency syndrome (AIDS) due to human immunodeficiency virus (HIV) (Gurubacharya et al., 2003).

In India, authentic data on NSI is scarce. It is not known exactly how many occupation related injuries occur each year and hence it is difficult to estimate an annual incidence (Rodrigues, 2010). The average percutaneous transmission rates for hepatitis B (HBV) and $\mathrm{C}(\mathrm{HCV})$ are $33.3(6-33 \%)$ and 3.3 percent (1$10 \%$ ), respectively, while the seroconversion risk for HIV is 0.31 percent (Muralidhar et al., 2006). Effectiveness of administration of post-exposure prophylaxis varies from 75 to more than $90 \%$ to prevent HBV infection. Post-exposure prophylaxis for HIV has also been shown to lower the risk of infection after sharp injuries. However, there is no known way of preventing $\mathrm{HCV}$ acquisition following NSI (Mehrdad et al., 2006). So prevention of sharp injury is the only recourse.

The present study addresses the important issue of Sharp injuries and aims at determining the occurrence of sharp injury among different categories of HCWs, the various factors associated, the circumstances under which they occur and the subsequent measures taken following a sharp injury.

\section{Materials and Methods}

A retrospective analysis was conducted from January 2014 to June 2015 at a tertiary care hospital of Mumbai. All the categories of Health care workers who had a sharp injury were included in the study. A proforma was filled up for the HCWs wherein the mode and route of injury, type of sharp and other associated factors were recorded. The sample of the source was tested for HIV and HCV antibodies as well as for HBsAg. The baseline status of the HCWs for HIV, HCV antibodies and HBsAg was also done. All the HCWs were followed up after 3 months for seroconversion.

Fischer Exact test and Chi-square test were used as the statistical tools for significance of associations.

\section{Results and Discussion}

A total of 105 sharp injuries were reported from January 2014 to June 2015. More than half of the HCWs were less than 25 years of age $(55.53 \%)$. Female HCWs more often reported the injury to the Microbiology department (61.9\%). Student population suffered the major brunt of injuries (70.4\%). The various student categories were interns, post graduate students, nursing students and DMLT students. Amongst these student categories, interns $(36.48 \%)$ and $1^{\text {st }}$ year PG students $(21.62 \%)$ suffered the maximum injuries. Class IV workers $(67.74 \%)$ and nursing staff $(19.35 \%)$ were the most common staff members who suffered an injury. Most of injuries were reported by the medicine department (28.57\%).

Hollow bore needles commonly caused the injuries in all the categories of HCWs $(82.85 \%) .(p=0.0000$ statistically significant at $\alpha=0.01$; Fischer Exact one tailed \& two tailed). Injuries by the solid bore needles were mostly seen in nursing staff and some post graduate students. $93 \%$ of the injuries were superficial pricks by the intradermal route. 5\% were splashes on the mucous membrane.

Almost all the injuries were self- inflicted $(96 \%)$. Recapping of needles was reported in $20.6 \%$ of the HCWs and was found to be a significant risk factor as analyzed by the Fischer exact test $(p=0.0000)-$ two tailed and one tailed; significant at $\alpha=0.01$ $(p<0.01)$. Injuries due to recapping of needles 
were most common with the students (22.97\%) (Table 1) (Figure 1) and was statistically significant by the Chi-square test.

The various risk factors that were associated with these sharp injuries were also analyzed. The status of the source was not known to the $\mathrm{HCW}$ in $81 \%$ of the injuries. In rest of the $19 \%$ injuries where the status of the source was known to the $\mathrm{HCW}, 50 \%$ were known to be seropositive for HIV antibodies. Serostatus of $\mathrm{HCV}$ antibodies and $\mathrm{HBsAg}$ was known in only one source of the reported injuries.

More than half of the injuries were seen in newly joined HCWs (53\%) (Figure 2).14.2\% of the HCWs gave a past history of needle stick injury.18.1\% HCWs had overworked for more than 8 hours on the preceding day of the sharp injury which was found to be a significant risk factor $-p=0.0000$ by Fischer Exact test (significant at $\alpha=0.01$ )

Only $57.1 \%$ of the HCWs had taken complete schedule of HBsAg vaccine. 26.6\% were incompletely vaccinated and $16.2 \%$ were not vaccinated at all. Only $6.7 \%(4 / 60)$ of the HCWs had done their anti HBs antibody titers and 3 HCWs had an acceptable anti HBs titer $\geq 10 \mathrm{IU}$.

Following a needle stick injury, $82.5 \%$ of the Health care workers followed the preliminary measures. $4.8 \%$ of the HCWs took only the preliminary measures without reporting to the ART center (Table 2). Out of the $91 \mathrm{HCWs}$ who took PEP, $70.3 \%$ took PEP within the first 2 hours of injury $(p=0.0313-$ Fischer exact test two tailed)

All the serum samples of the source were tested for detection of HIV antibodies as per the NACO guidelines using the Strategy III, as well as for presence of $\mathrm{HBsAg}$ and antibodies to Hepatitis $\mathrm{C}$ virus each by the
ELISA test. $6.7 \%$ of the source samples were found to be seropositive for HIV antibodies; 1 source was seropositive for HBsAg only. All the sources of injuries were seronegative for HCV antibodies.

The baseline status of the Health care workers for these three parameters was also done. All the Health care workers was seronegative for HIV antibodies, HBsAg and hepatitis $\mathrm{C}$ antibodies. None of the Healthcare workers seroconverted till 3 months of follow up.

\section{Results and Discussion}

NSIs are one of the underreported problems in health care workers 5 . In our study, the majority of the HCWs who had NSIs were interns and residents. Though interns form a small proportion of the health care workers, they accounted for a large proportion of the injuries. According to Jayanth et al., this could be a reflection of the larger number of exposure prone procedures conducted by interns.

All the categories of HCWs had injuries most commonly due to hollow bore needles (Rahul et al., 2010). The hollow bore needles include hypodermic needles, blood collection needles, butterfly needles and IV catheter stylets and injuries by such needles are of particular concern, since they are likely to contain residual blood and are associated with an increased risk for blood borne virus transmission (Adams, 2012). Sharp injuries by solid bore needles in our study were $9.52 \%$ in contrast to $20.9 \%$ that was reported by Jayanth STetal ${ }^{6}$. Solid sharps such as suture needles or scalpels, generally deliver a smaller blood inoculum, especially if they first penetrate gloves or another barrier. Therefore these devices theoretically pose a lower risk for HIV transmission. Similar descriptive data are not available for type of 
devices or exposures involved in transmission of $\mathrm{HBV}$ or HCV.

$18 \%$ of sharp injuries occurred while recapping in contrast to $66.3 \%$ reported by Murlidhar et al., and $8.5 \%$ reported by Jayanth et al., (2009). Recapping of needles was most common with the students and the nursing staff. There is need for safety training to be a regular activity with periodic bolstering. IEC material should be displayed prominently at the places of work, emphasizing the point about no recapping.

The status of the source for HIV was known in only $19.04 \%$ of the HCWs. In the remaining $81 \%$ of the cases, status of the source was not known to the HCWs which is almost same as reported by Gurbacharya et $a l^{2}$. Though the risk of transmission of Hepatitis B \& C infections is more, $18.09 \%$ of the HCWs knew only the HIV status of the Source. The HBsAg and anti HCV status was known in only 1 case. The average percutaneous transmission rates for hepatitis $\mathrm{B}(\mathrm{HBV})$ and $\mathrm{C}(\mathrm{HCV})$ are 33.3(6-33\%) and 3.3 percent $(1-10 \%)$, respectively, while the seroconversion risk for HIV is 0.31 percent. Thus, increasing staff awareness and educating them on NSI issues is a felt need. It is also important that all patients should be tested for HBsAg and anti HCV antibody.

Table.1 Circumstance of injury amongst the HCWs

\begin{tabular}{|c|c|c|c|c|c|}
\hline $\begin{array}{c}\text { Circumstance } \\
\text { of Injury }\end{array}$ & $\begin{array}{c}\text { Staff } \\
(\mathbf{n = 3 1})\end{array}$ & $\begin{array}{c}\text { Students } \\
(\mathbf{n = 7 4 )}\end{array}$ & $\mathbf{p}$ value & $\begin{array}{c}\text { Statistical } \\
\text { significance }\end{array}$ & Method used \\
\hline Recapping & 02 & 17 & 0.044866 & $\begin{array}{c}\text { Significant } \\
\text { at } \mathrm{p}<0.05 \& \\
\text { at } \mathrm{p}<0.10\end{array}$ & Chi square test \\
\hline Handling & 20 & 52 & 0.562346 & $\begin{array}{c}\text { Not } \\
\text { significant }\end{array}$ & Chi square test \\
\hline Cleaning & 09 & 05 & 0.977929 & $\begin{array}{c}\text { Not } \\
\text { significant }\end{array}$ & Chi square test \\
\hline
\end{tabular}

Sharp Injuries are significant with recapping of needles.

Table.2 Actions taken by the HCWs following a sharp injury

\begin{tabular}{|c|c|}
\hline \multicolumn{1}{|c|}{ Steps taken } & Number (\%) \\
\hline $\begin{array}{c}\text { Preliminary measures } \\
\text { (Allowing the wound to bleed freely, washing with } \\
\text { soap\& water \&/or cleaning with spirit) }\end{array}$ & $05 / 105(4.76 \%)$ \\
\hline Preliminary measures + MICU reporting & $09 / 105(8.57 \%)$ \\
\hline Preliminary measures + MICU reporting + PEP & $87 / 105(82.50 \%)$ \\
\hline MICU reporting + PEP & $04 / 105(3.81 \%)$ \\
\hline
\end{tabular}

Preliminary measures alongwith post exposure prophylaxis (PEP) was followed by $82.5 \%$ HCWs. 
Fig 1 Circumstance of injury in the HCWs

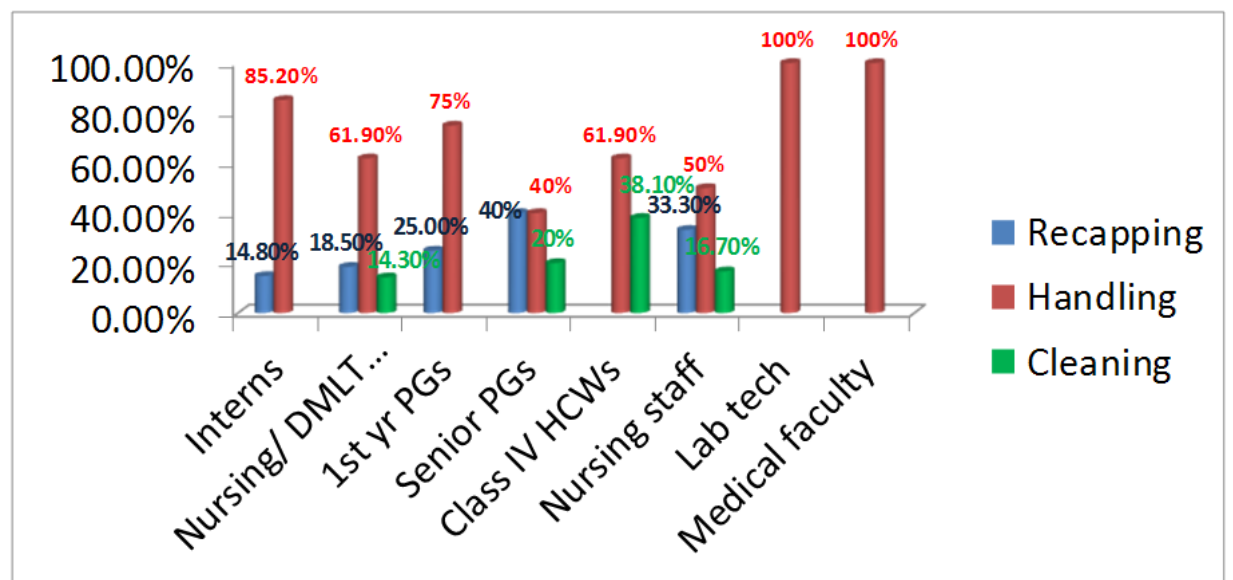

Recapping of needle was commonly observed in student population

Fig 2 Length of employment of the HCWs

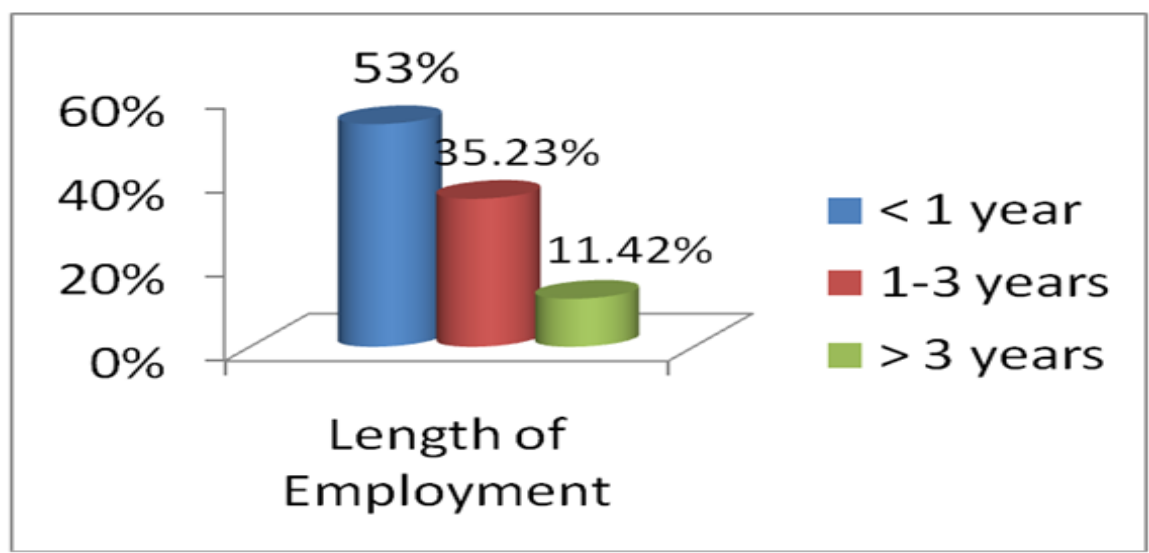

More than half of the sharp injuries in newly joined HCWs

53\% injuries occurred in HCWs who were employed for less than a year as also seen in other studies that injuries were common in those with less work experience. Past history of NSI was reported in $14.3 \%$ of the HCWs in contrast to $74 \%$ by Gurbacharya et al., Only $57.1 \%$ of the HCWs had completed the hepatitis B vaccination as also reported by Gurubacharya et al., as $60 \%$. Around $16.1 \%$ of the HCWs were not vaccinated at all. In many health facilities, even though the personnel are vaccinated, the seroconversion status after vaccination is not assessed. Only $6.7 \%$ of the HCWs who had completed the hepatitis B vaccination did their anti HBs antibody titer in contrast to $14 \%$ as reported by Gurubacharya et al., (2010). Preliminary measures like hand washing with soap and water was practiced by about $95.7 \%$ of the HCWs and $86.3 \%$ took post exposure prophylaxis in addition to hand washing. In a study done by Sharma et al., (2010) $60.9 \%$ of the HCWs washed the site of injury with soap and water but only $7.8 \%$ took PEP. The high rate of taking PEP in our study was probably because the $\mathrm{HCWs}$ were first referred to MICU/ ART center for at least the first dose of PEP before taking the samples for testing at the Microbiology Department. Approximately 
$60 \%$ of the HCWs took PEP within the first 2 hours of injury which was found to be statistically significant

$(p=0.0313-$ Fischer exact test two tailed $)$.

In conclusion, sharp injuries represent an omnipresent occupational hazard that people working in a hospital face daily. Prevention of sharp injury is the best way to prevent several diseases in HCWs. There is much room for improvement in protecting the HCWs from a sharp injury, which can be accomplished through a combination of comprehensive programmes like stress on institutional behaviour and device related factors that contribute to the occurrence of these injuries, ensuring adequate training in safe use and disposal of needles, putting in place a culture of incident reporting and following preventive practices like vaccinations for hepatitis B (Sumathi et al., 2010).

\section{References}

Adams, D. 2012. Needlestick and sharps injuries: implications for practice. Nursing Standard. 26, 37, 49-57. Date of acceptance: March 212012.

Gurubacharya, D.L., K.C. Mathura, Karki, D.B. 2003. Knowledge, attitude and practices among health care workers on needle-stick injuries. Kathmandu Univ. Med. J., Vol. 1 (2), 91-94.

Jayanth, S.T., H. Kirupakaran, K.N. Brahmadathan, L. Gnanaraj, G. Kang. 2009. Needle stick injuries in a tertiary care hospital. Indian J. Med. Microbiol., 27(1): 44-47.

Mehrdad Askarian, Leila Malekmakan. 2006. The prevalence of needle stick injuries in medical, dental, nursing and midwifery students at the University teaching hospitals of Shiraz, Iran. Indian J Med Sci., 60(6).

Muralidhar, V., Muralidhar, S. 2006. Safety and risk management. In: Muralidhar V, Muralidhar S, editors. Hospital acquired infections-power strategies for clinical practice. New Delhi: Viva Books Pvt. Ltd. p.110.

Rahul Sharma, S.K., Rasania, Anita Verma, Saudan Singh. 2010. Study of Prevalence and Response to Needle Stick Injuries among Health Care Workers in a Tertiary Care Hospital in Delhi, India. Indian J. Community Med. 35(1).

Rele, M., Mathur, M., Turbadkar, D. 2002. Risk of needle stick injuries in health care workers - A report. Indian J. Med. Microbiol., 20: 206-207.

Rodrigues. 2010. Needle stick injuries \& the health care worker - the time to act is now- A commentary Indian J. Med. Res., 131, 384-386

Sumathi Muralidhar, Prashant Kumar Singh, R.K. Jain, Meenakshi Malhotra \& Manju Bala. 2010. Needle stick injuries among health care workers in a tertiary carehospital of India. Indian J. Med Res., 131, 405-410.

Workbook for Designing, Implementing and Evaluating a Sharps Injury Prevention Program http://www.cdc.gov/sharps safety/part1TEXTONLY.html.

\section{How to cite this article:}

Mrudul Randive, Anita Ramchandran, Dilip Turbadkar and Sujata Baveja. 2017. An Audit of Sharp Injuries at a Tertiary Care Hospital in Mumbai, India. Int.J.Curr.Microbiol.App.Sci. 6(1): 201-206. doi: http://dx.doi.org/10.20546/ijcmas.2017.601.025 